\title{
The Corrosion Degradation Characters of the Secondary Loop Piping in Nuclear Power Plant
}

\section{Liang Zhao ( $\nabla$ zhaol01@cnnp.com.cn )}

East China University of Science and Technology https://orcid.org/0000-0002-2704-4156

Kunjie Luo

Suzhou Nuclear Power Institute

Guangfu Li

Shanghai Research Institute of Materials

Shantung Tu

East China University of Science and Technology

\section{Original Article}

Keywords: nuclear power, secondary loop pipe, flow accelerated corrosion, erosion corrosion

Posted Date: January 9th, 2021

DOI: https://doi.org/10.21203/rs.3.rs-141378/v1

License: (c) (1) This work is licensed under a Creative Commons Attribution 4.0 International License. Read Full License 


\title{
The corrosion damage characters of the secondary loop piping in nuclear power plant
}

\author{
Liang Zhao ${ }^{1}$, Kunjie Luo ${ }^{2}$, Guangfu $\mathrm{Li}^{3}$, Shantung $\mathrm{Tu}^{1}$ \\ Received June xx, 201x; revised February xx, 201x; accepted March xx, 201x \\ (C) Chinese Mechanical Engineering Society and Springer-Verlag Berlin Heidelberg 2017
}

\begin{abstract}
Fully understanding the corrosion damage characteristics of the secondary loop pipeline plays an important role in ensuring the safe, stable and economic operation of a nuclear power plant. flow accelerated corrosion(FAC), erosion corrosion(EC), high temperature corrosion(HTC) and under insulation corrosion(UIC) are the main corrosion damage forms of secondary loop pipeline. The damage characteristics of FAC in liquid single-phase flow and vapor-liquid two-phase flow are obviously different. Under specific operating conditions, different EC damages such as flash evaporation, droplet impact, HTC erosion, cavitation corrosion, jet cutting, etc may occur. In this paper, the formation conditions, damage morphology, wall thickness distribution, thinning rate and other characteristics of corrosion damage of secondary loop pipeline in nuclear power plant are compared and analyzed. On this basis, these corrosion damages of the secondary loop pipeline in nuclear power plant could be effectively identified and targeted managed.
\end{abstract}

Keywords: nuclear power - secondary loop pipe • flow accelerated corrosion $\bullet$ erosion corrosion

\section{Introduction}

The function of the secondary loop of the nuclear power plant is to introduce the high temperature and high pressure steam generated in the steam generator into the steam turbine to generate power, then heat the condensate water step by step to the steam generator, and maintain the continuous operation of this steam water cycle. Low

Liang Zhao

zhaol01@cnnp.com.cn

1 Key Laboratory of Pressure Systems and Safety, Ministry of Education, East China University of Science and Technology, Shanghai 200237

2. Life Management Center, Suzhou Nuclear Power Research Institute, Suzhou215004.

3. Shanghai Key Lab of Engineering Materials Application and Evaluation, Shanghai Research Institute of Materials, Shanghai 200437. carbon steel is often used as secondary loop pipe material. Figure 1 shows the heat balance diagram of the secondary loop of a nuclear power plant. The secondary loop flow are vapor single phase flow, vapor-liquid two-phase flow and liquid single phase flow. The main purpose of secondary loop water chemistry is to create a reducing condition with low corrosion for the steam generator and other important components. The dissolved oxygen content was controlled below 10ppb. The $\mathrm{pH}$ was controlled between $9.6 \sim 9.8$ $\left(25^{\circ} \mathrm{C}\right)$ [1]. The corrosion rate of the low carbon steel pipeline is generally slow under this condition, and the total iron in the feed water could be controlled at about $1 \mathrm{ppb}$. However, due to the low dissolved oxygen content, it is not conducive to the formation of stable and dense oxide film on the inner wall of the low carbon steel pipe, resulting in the thinning of FAC at the local position of the pipeline.

In addition, due to the structural or pressure change downstream of some valves, orifices and other equipment, the phase state and flow state could be changed, not only the thinning of FAC could be aggravated, but also EC could be caused [2]. FAC and EC are the main corrosion damage forms of secondary loop pipeline in nuclear power plant. Operation experience also shows that HTC will occur in high temperature air drainage pipeline, which will cause thinning and blockage, and UIC in specific environment is also the hidden danger that threatening pipeline integrity. On December 9, 1986, a secondary loop pipe of Surry nuclear power plant in the United States ruptured, causing 4 deaths and 4 serious injuries; on August 9, 2004, a secondary loop pipeline of Mihama nuclear power plant in Japan ruptured, causing 4 deaths and 7 injuries. There have been hundreds of secondary loop pipeline rupture events caused by corrosion damage all over the world.[3] Therefore, it is necessary to investigate the formation mechanism, Macro and micro morphology, wall thickness distribution and corrosion rate of these corrosion damage forms. 


\section{Damage characteristics of FAC}

A downstream pipe section of the single-stage single hole orifice of the feed water pump warm-up pipeline was selected for tracking analysis. The pipe medium is liquid single-phase flow. The operating temperature is $142{ }^{\circ} \mathrm{C}$. The pipe material is ASME SA106B with $0.10 \% \mathrm{Cr}$. The nominal pipe size is DN20, and the nominal wall thickness is $3.92 \mathrm{~mm}$, he orifice diameter is $5 \mathrm{~mm}$. The flow velocity reached the maximum value of $30 \mathrm{~m} / \mathrm{s}$ at 1.5 times inner diameter from the orifice according to calculation, which is the FAC sensitive position.

In the initial stage of the pipeline operation, a relatively uniform and smooth $\mathrm{Fe}_{3} \mathrm{O}_{4}$ oxide film was formed on the inner wall at high temperature, as shown in Fig. 3 (a). The energy spectrum showed that the oxide film is composed of $\mathrm{O}$ and $\mathrm{Fe}$, the atomic percentage of $\mathrm{Fe}$ is $43.32 \%$, which is consistent with the content of $\mathrm{Fe}$ in $\mathrm{Fe}_{3} \mathrm{O}_{4}$. After the pipeline was put into normal operation, the flow rate increases, and the oxide film at the sensitive position of FAC dissolved locally, causing local corrosion damage. As shown in Fig. 3 (b), there are shallow corrosion pits on the inner wall of the pipeline. 18 months after the pipeline was put into operation, a strip thinning area with large width but shallow depth appeared on the inner wall of the pipeline, as shown in Fig. 3 (c). The thinning area at the sensitive position of FAC was narrow and deep, and then became wide and shallow along the flow direction. There are large pits with irregular shape on the thinning area. The width of the large pits at the sensitive position of FAC is about $300 \mu \mathrm{m}$, and then gradually increases to $500 \mu \mathrm{m}$ along the flow direction. The energy spectrum showed that the atomic percentage of $\mathrm{Fe}$ is $60.19 \%$ at the bottom of the pit, which is significantly higher than that of $\mathrm{Fe}_{3} \mathrm{O}_{4}$, indicating that the surface oxide film has been damaged. After the pipeline has been put into operation for 37 months, small round pits formed at the sensitive position of FAC, as shown in Fig. 3 (d). The diameter of the pits was about 300 400 $\mathrm{\mu} \mathrm{m}$, and then these pits gradually become large and sparse along the flow direction. As shown in Fig. 3 (e), traces of local dissolution of oxide film under the action of fluid can be found at the bottom of the pit. The maximum thinning rate was $0.19 \mathrm{~mm} / \mathrm{a}$, and the wall thickness of the thinning area and the non thinning area transits smoothly. 56 months after the pipeline was put into operation, the pits at the sensitive position of FAC densely distributed in orange peel shape [8], as shown in Fig. 3 (f), the diameter of the pits is about 100 150 $\mu \mathrm{m}$, and the energy spectrum showed that the percentage of iron atoms in the inner wall of the pipeline is $62.28 \%$. The maximum thinning rate is $0.22 \mathrm{~mm} / \mathrm{a}$. The thickness of the thinning zone and the non thinning zone transits smoothly. 74 months after the pipeline has been put into operation, the pits on the inner wall of the pipeline got smaller and denser, as shown in Fig. 3 (g). The pits at the sensitive position of FAC densely distributed in orange peel shape, and the diameter of the pits is about $100-150 \mu \mathrm{m}$. The oxide film dissolution traces at the bottom of the pits is obviously shown in Fig. 3 (h), no complete oxide film could be found. The percentage of $\mathrm{Fe}$ atom reached $66.2 \%$. The maximum thinning rate is $0.3 \mathrm{~mm} / \mathrm{a}$. It can be seen that $\mathrm{FAC}$ rate increases with the dissolution of oxide film. As shown in Figure 3 (i), the pits formed by FAC at the severe thinning area are small and dense, and then gradually become large and sparse along the flow direction. The wall thickness of the pipeline from the thinning area to the non thinning area has a smooth transition, and there were no obvious mutation, which is related to the relatively stable local flow pattern and flow field of the liquid single-phase flow .

\subsection{Damage characteristics of FAC in vapor-liquid two-phase}

\section{flow}

The downstream pipe section of single-stage single orifice orifice of main steam valve drainage pipeline was selected for tracking analysis. The medium in the pipe is vapor-liquid two-phase flow. The operating temperature is about $170{ }^{\circ} \mathrm{C}$, and the pipe material is ASME SA106B with $0.10 \% \mathrm{Cr}$. The nominal pipe size is DN25, and the nominal wall thickness is $4.51 \mathrm{~mm}$, he orifice diameter is $5 \mathrm{~mm}$. The flow velocity reached the maximum value of $40 \mathrm{~m} / \mathrm{s}$ at 2 times inner diameter from the orifice according to calculation, which is the FAC sensitive position. In the process of temperature and pressure rise at the initial stage of pipeline operation, a relatively uniform and smooth $\mathrm{Fe}_{3} \mathrm{O}_{4}$ oxide film was formed on the inner wall of the pipeline at high temperature, as shown in Fig. 4 (a). After the pipeline was put into normal operation, the flow rate increases, and the oxide film at the FAC sensitive position on the inner wall dissolves locally. As shown in Fig. 4 (b), local corrosion damage occurred, and there are irregular corrosion pits distributed along the flow direction. The flow pattern of vapor-liquid two-phase flow is more complex than that of liquid single-phase flow. The mass transfer rate of ions in two-phase flow is also higher, and the dissolution rate of oxide film is faster. Compared with the local corrosion damage of liquid single-phase flow, more corrosion pits were formed, and the corrosion damage is relatively serious. 37 months after the pipeline was put into operation, the thickness of FAC sensitive position decreased obviously, the maximum thinning rate is $0.2 \mathrm{~mm} / \mathrm{a}$, and the wall thickness of thinning area and non thinning area transits smoothly. The local inner wall of 
FAC sensitive position presents black and white tiger pattern as shown in Fig. 4 (c), and the tiger pattern gradually disappears along the flow direction and turns into black horseshoe pit as shown in Fig. 4 (d). 74 months after the pipeline was put into operation, the whole circle thinning occurred in the range of 1-3 times of the inner diameter from the orifice, as shown in Fig. 4 (e), and the maximum thinning rate is $0.3 \mathrm{~mm} / \mathrm{a}$, the tiger spot pattern can no longer be found in the thinning area, but is covered with horseshoe pits as shown in Fig. 4 (f). The diameter of horseshoe pits is about $0.5 \mathrm{~mm}$ to $1 \mathrm{~mm}$. There are tiger spots at the transition location between the thinning area and non thinning area, and the wall thickness changes suddenly. It shows that the dissolution rate of $\mathrm{Fe}_{3} \mathrm{O}_{4}$ oxide film is faster in the vapor-liquid two-phase environment, and the corresponding FAC thinning rate is higher. With the damage and disappearance of oxide film, FAC rate also increases significantly..

\section{Damage characteristics of EC}

EC refers to the physical damage on the pipeline inner surface under the action of fluid erosion. The EC of the secondary loop pipeline mainly includes HTC erosion, droplet impact, cavitation corrosion, flash erosion. Jet cutting damage of the liquid single-phase flow will also appear when the design is improper. Droplet impact causes by the continuous and discrete impact of liquid particles on the metal surface driven by high-speed steam flow. Droplet impact erosion often forms evenly distributed punctate impact pits on the inner surface of the last stage blades of the steam turbine, the cylinder blocks in the low pressure cylinder, the upper titanium tubes of the condenser and the connecting pipes from the high pressure cylinder to the moisture separator reheater, with the diameter of about tens to hundreds of microns.

Cavitation corrosion is a physical erosion of high-frequency fatigue damage on the inner wall of pipeline caused by the collapse and burst of a large number of tiny bubbles compressed by high-pressure fluid. When the bubble breaks, all the energy is concentrated at the breaking point, and the shock wave pressure can reach $2000 \mathrm{MPa}$, which is much higher than the strength of the metal, the surface metal would be teared, and rough slag holes would be formed [2].

Flash erosion occurs when the pressure of high-temperature and high-pressure flow suddenly drops to the saturated vapor pressure, the liquid phase vaporizes rapidly and the volume expands rapidly, causing the fluid to accelerate the impact on the inner wall of the pipeline. When the fluid is mainly in vapor phase, flashing actually accelerates the droplet impact erosion, while when the fluid is mainly in liquid phase, flashing accelerates the fluid to form smooth wear marks on the inner wall of the pipeline.

Jet cutting of liquid single-phase flow refers to the mechanical cutting damage of metal matrix caused by a small stream of high-speed fluid, and the narrow and deep grooves are cut along the flow direction on the inner wall of the pipeline.

HTC erosion occurs when the oxidation reaction directly produced on the metal surface by the high temperature flow, which forms a brittle and loose oxide layer on the metal surface. This oxide layer is broken by high-speed fluid impact. Then the exposed metal surface continues to be oxidized at high temperature to form loose oxide layer, which is broken by high-speed fluid impact and then taken away. The repeated formation and breakage of oxide layer accelerate the corrosion damage of pipeline. Macroscopically, the erosion damage of HTC presents the riverbed morphology, and the ruptured oxide layer could be found on the thinning location .

Figure 5 shows the EC damage morphology of the pipeline downstream of the steam trap of the high pressure heater in a nuclear power plant. The upstream of the steam trap is liquid single-phase flow. The operating temperature is $170{ }^{\circ} \mathrm{C}$, and the pressure head of the steam trap is 1.2MPa. The material of the downstream pipeline is ASME SA106B. The nominal pipe size is DN50, and the nominal wall thickness is $5.54 \mathrm{~mm}$. The small opening action of the steam trap produces high pressure jet flow, and the calculated flow rate can reach $177 \mathrm{~m} / \mathrm{s}$. The metal on the pipe wall is directly jet cut to form the groove with neat boundary in Fig. 5 (a). The thickness at the groove has been reduced from $5.54 \mathrm{~mm}$ to $1.5 \mathrm{~mm}$. At the same time of jet cutting, the high temperature and high pressure water flash, which aggravates the fluid erosion on the pipe wall, resulting in the overall thinning of the pipeline. As shown in Fig. 5 (b), except for the location of the jet cutting groove, other thinning positions are smooth and flat, which are flash erosion morphology. High speed fluid not only caused jet cutting and flash erosion damage to the downstream pipeline of the trap, but also formed serious cavitation corrosion on a pipe socket about $500 \mathrm{~mm}$ downstream of the trap. As shown in Figure 5 (c), the cavitation corrosion area is densely covered with rough round slag holes. In the most serious damage area, the slag holes are large and deep, with the maximum diameter of about $10 \mathrm{~mm}$. Then, the slag holes gradually become smaller along the flow direction, with the minimum diameter of about $2 \mathrm{~mm}$. As the cavitation corrosion damage gradually weakens, the small slag holes change to 
small pits with a diameter of less than $2 \mathrm{~mm}$.

Figure 6 shows the appearance of HTC erosion damage on the inner surface of a pipe section. The pipe is the high-pressure cylinder drain pipe of a nuclear power plant. There is a single-stage single hole orifice upstream of the pipe. The material of the pipeline is ASME SA106B. The nominal pipe size is DN25, and the nominal wall thickness is $4.51 \mathrm{~mm}$. The diameter of the orifice is $3 \mathrm{~mm}$. The operating temperature is $216{ }^{\circ} \mathrm{C}$. The pressure head of the orifice is $1.95 \mathrm{MPa}$, and the maximum flow velocity at the downstream thinning of the orifice is about $90 \mathrm{~m} / \mathrm{s}$. The erosion thinning part presents the riverbed shape and smooth groove shape along the flow direction as shown in Figure 6 (a). In Figure 6 (b), the cracked oxide layer can be discovered at the thinning location. The maximum thinning rate of the pipe section is about $0.5 \mathrm{~mm} / \mathrm{y}$.

\section{Damage characteristics of HTC}

HTC could be acceptable for most of the secondary loop components because of the low corrosion rate, but not for the air drainage pipeline. the air drainage pipelines directly drain water from the high temperature equipment to the plant environment. The high temperature, moist steam, saturated oxygen and piping vibration in the air drainage pipeline create sufficient corrosion conditions. Although the air drainage pipeline is not the pressure boundary of the secondary loop high-energy pipeline, its products easily cause blockage in a short time, which will make the system function lost and affect the safe operation of equipment.

Figure 7 [9] shows the corrosion thinning and blockage of the gland seal steam drainage pipeline of the reheat main steam valve in a nuclear power plant. The pipe material is JIS g3454 (stp410) low carbon steel. The nominal pipe size is DN15, the nominal wall thickness is $3.73 \mathrm{~mm}$. The operating temperature of the reheat main steam valve is $200^{\circ} \mathrm{C}$. There is serious thinning near the reheat main steam valve (see Figure 7 (a)), the thinning rate reaches $0.4 \mathrm{~mm} / \mathrm{a}$. The thinning pipe section is filled with corrosion products (see Fig. 7 (b)). The drain water vaporized rapidly in the air drainage pipeline due to the sudden drop of pressure. Under high temperature and saturated oxygen condition in the pipeline, the water vapor, oxygen and metal reacted rapidly to form a loose oxide film. At the same time, the pipeline vibration caused large alternating stress in the pipe section. Thus, the continuous rupture of the film and the further corrosion of the metal are promoted. The accumulation of corrosion products hindered the flow and kept the temperature and humidity in the pipe at a high level, thus further aggravating the HTC.

\section{Damage characteristics of UIC}

The insulation layer is not conducive to the diffusion of temperature and humidity on the external surface of the pipeline. UIC mainly occurs on the outdoor branch pipe of the main steam pipe and the main feed water pipe. during the normal operation of the secondary loop, the rainwater infiltrated in the main steam pipe and the main feed water pipe insulation is heated and evaporated, and the insulation layer remains dry. While the water in the branch pipes insulation could not to be evaporated due to the relatively low temperature, which leads to the long-term warm and humid corrosion environment in the insulation. Under the combined action of temperature, pressure fluctuation, vibration and other factors, the high-temperature anti-corrosion coating on the outer wall of the branch pipeline could be rapidly damaged and failed, and the metal matrix could be constantly corroded. It should be noted that the thinning rate of the pipeline may reach 0.3 $\mathrm{mm} / \mathrm{a}$ even at room temperature.

Figure 8 shows the macroscopic appearance of serious corrosion on the outer surface of the main steam flow pressure pipeline of a nuclear power plant. The pipeline is an outdoor insulation pipeline directly connected with the main steam pipe. During the operation, the interior of the insulation layer had kept warm and humid for a long time, resulting in the rapid corrosion and thinning of the low-carbon steel pipeline.

\section{Comparative analysis of corrosion damage characteristics}

The formation conditions, macro and micro morphology, wall thickness distribution, thinning rate and other characteristics of FAC, EC, HTC and UIC damages in the secondary loop pipeline of nuclear power plant are summarized, as shown in Tab.1.

The formation of FAC damage is mainly affected by the $\mathrm{Cr}$ content, temperature and flow velocity. The FAC sensitive temperature of two-phase flow and liquid single-phase flow are different. The formation of EC is mainly related to the phase state change and flow rate caused by the change of temperature and pressure. HTC mainly occurs in the air drainage pipeline of high temperature equipment, while UIC mainly occurs on the outer surface of outdoor insulation pipeline with relatively low temperature.

FAC forms uniform and dense small corrosion pits on the pipe inner wall in liquid single-phase flow, which are orange peel like. With the decrease of corrosion, the corrosion pits gradually become large and sparse. Two-phase flow FAC damage causes horseshoe pit 
morphology in the thinning area. The damage morphology of EC is related to the specific damage form. The jet cutting of high-speed liquid flow forms narrow and deep grooves. The impact of droplets forms uniform and dense impact pits. The flash erosion dominated by steam phase actually intensifies the impact of droplets. The flash erosion dominated by liquid phase forms flat and smooth wear marks. The high-temperature corrosion erosion presents riverbed like and smooth groove like along the flow direction. The cavitation corrosion forms rough slag hole, and the slag hole gradually becomes smaller as the corrosion getting light. A large amount of corrosion products block the air drainage pipeline when HTC occurs.

The thickness transition of the FAC damage pipeline in liquid single-phase flow between the thinning zone and the non thinning zone is smoothly. The FAC in two-phase flow has a great influence on the wall thickness, which is concentrated in the local thinning. The whole ring thinning occurs when the pipe diameter is small. Flash erosion and droplet impact cause uniform corrosion thinning, and other EC damages cause a large degree of local mutation of the thickness, which is related to the corresponding erosion mechanism. Jet cutting makes the pipe wall thinning along the fluid cutting direction, cavitation corrosion slag hole also causes local wall thickness mutation, and the thickness of riverbed like thinning area caused by HTC erosion is also different from that of non thinning area. Local thinning occurs in high temperature air drainage pipeline, and uniform corrosion thinning occurs in outdoor insulation branch pipe.

The thinning rate of droplet impact and liquid single-phase FAC is relatively slow, while the corrosion rate of other corrosion damage forms is relatively fast. Pipe could rupture in a short time due to jet cutting and cavitation corrosion.

\section{Conclusions}

FAC, EC, HTC and UIC are The main forms of corrosion damage of secondary loop pipeline in nuclear power plant. FAC is affected by material, structure and environment, and the corrosion damage characteristics in liquid single-phase flow and two-phase flow are different. Under different operating conditions. EC damages, such as flash evaporation, droplet impact, HTC erosion, cavitation corrosion, jet cutting, etc may occur according to the corresponding formation mechanism. HTC and UIC damage will also appear under certain conditions, which will threaten the pipeline integrity. These corrosion damage forms of the secondary loop pipeline in nuclear power plant can be effectively identified according to the macro and micro morphology, wall thickness distribution, thinning rate and other characteristics concluded in this paper. So that targeted actions can be carried out to ensure the integrity and reliability of the secondary loop pipeline in the service life.

\section{Declaration}

\section{Acknowledgements}

The authors sincerely thanks to Professor ** of ** University for his critical discussion and reading during manuscript preparation.

\section{Funding}

Not applicable

\section{Availability of data and materials}

The datasets supporting the conclusions of this article are included within the article.

\section{Authors' contributions}

The authors' contributions are as follows: ** was in charge of the whole trial; ** wrote the manuscript; ** assisted with sampling and laboratory analyses.

\section{Competing interests}

The authors declare no competing financial interests.

\section{Consent for publication}

Not applicable

\section{Ethics approval and consent to participate \\ Not applicable}

\section{References}

[1] Zhao Liang, Hu Jianqun, Wu Zhigang, Wang Xin.Investigation on Flow Accelerated Corrosion Mitigation of Secondary Circuit Piping[J]. CHINESE JOURNAL OF MECHANICAL ENGINEERING.2011,24(2):214-219.

[2] Zhao Liang,Luo Kunjie, Li Guangfu.Corrosion degradation characteristics analysis and sensitive point identification of secondary circuit pipeline in nuclear power plant $[\mathrm{J}]$. Corrosion and protection.2016,37(7):579-585.

[3] Zhao Liang, Hu Jianqun, Wu Zhigang, Wang Xin. Discussion on flow accelerated corrosion management of secondary loop pipeline in nuclear power plant. Advanced technology of pressure vessel[M], Beijing: Chemical Industry Press,2009.

[4] EPRI. Flow-Accelerated Corrosion in Power Plants[R]. TR-106611-R1, 1998.

[5] EPRI. Residual Chromium Effects on Flow-Accelerated Corrosion of Carbon Steel [R].1011837, 2006.3.

[6] Zhao Liang, Luo Kunjie, Hu Jianqun, Wang Xin, Chen Mingjun. 
Failure Analysis and Strategy Investigation on Local Thinning of the Warm-up Line in Feed Water Pump. [C]21th International Conference on Nuclear Engineering.2013.7

[7] EPRI. Recommendations for an effective Flow-Accelerated Corrosion Program[R].NSAC-202L-R3, 2006.5

[8] Zhao Liang, Hu Jianqun, Wu Zhigang, Wang Xin.Flow accelerated corrosion management of secondary pipeline in Qinshan 3 nuclear power plant.Research progress of pressure pipeline technology [M], Beijing: Chemical Industry Press, 2010

[9] Zhao Liang, Zhao Ting, Li Guangfu. Failure analysis of shaft seal steam drainage pipeline of reheat main steam valve [J]. Corrosion and protection, 2013,34 (5): 458-462

\section{Appendix}

Appendix and supplement both mean material added at the end of a book. An appendix gives useful additional information, but even without it the rest of the book is complete: In the appendix are forty detailed charts. A supplement, bound in the book or published separately, is given for comparison, as an enhancement, to provide corrections, to present later information, and the like: A yearly supplement is issue. 

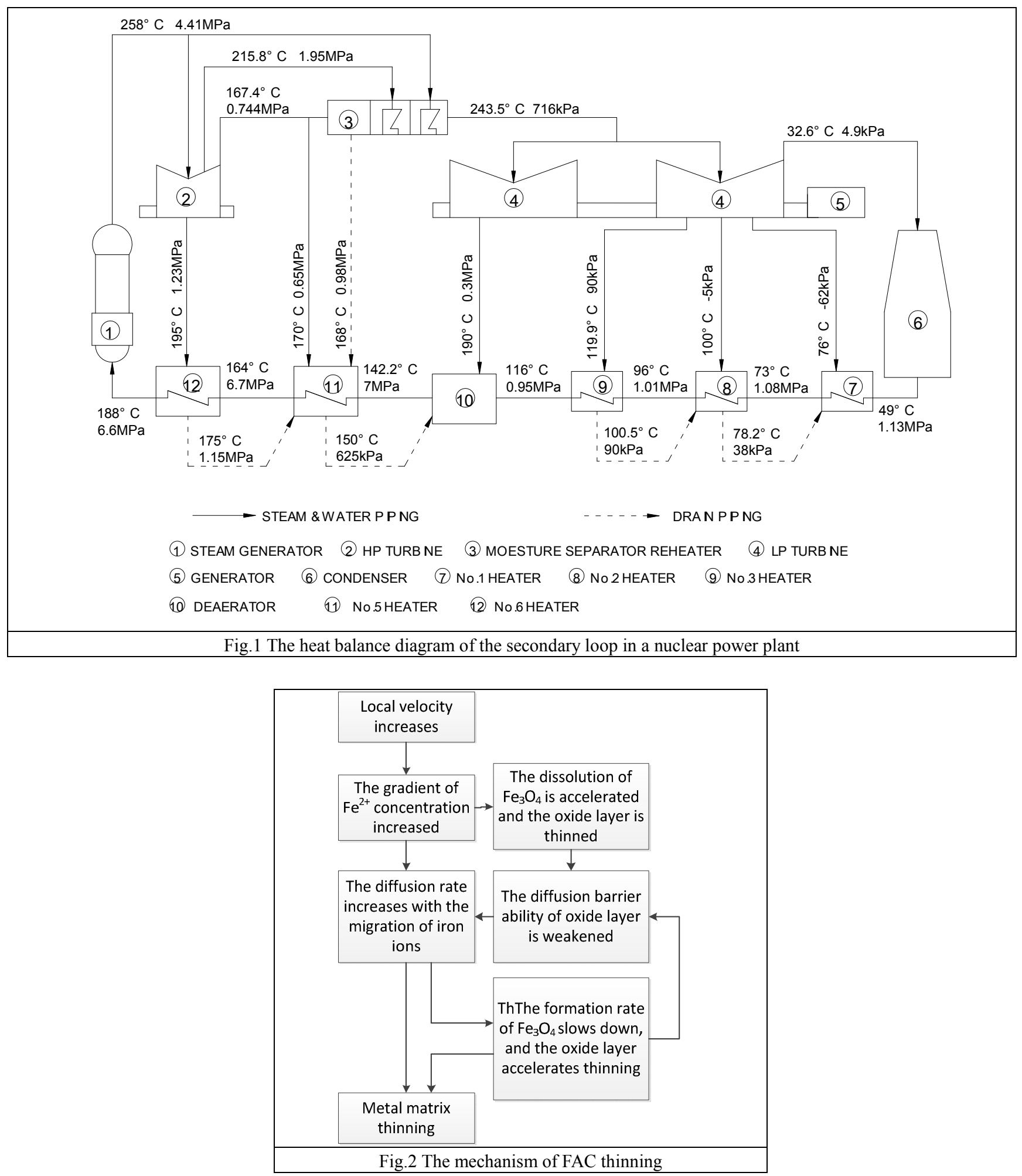


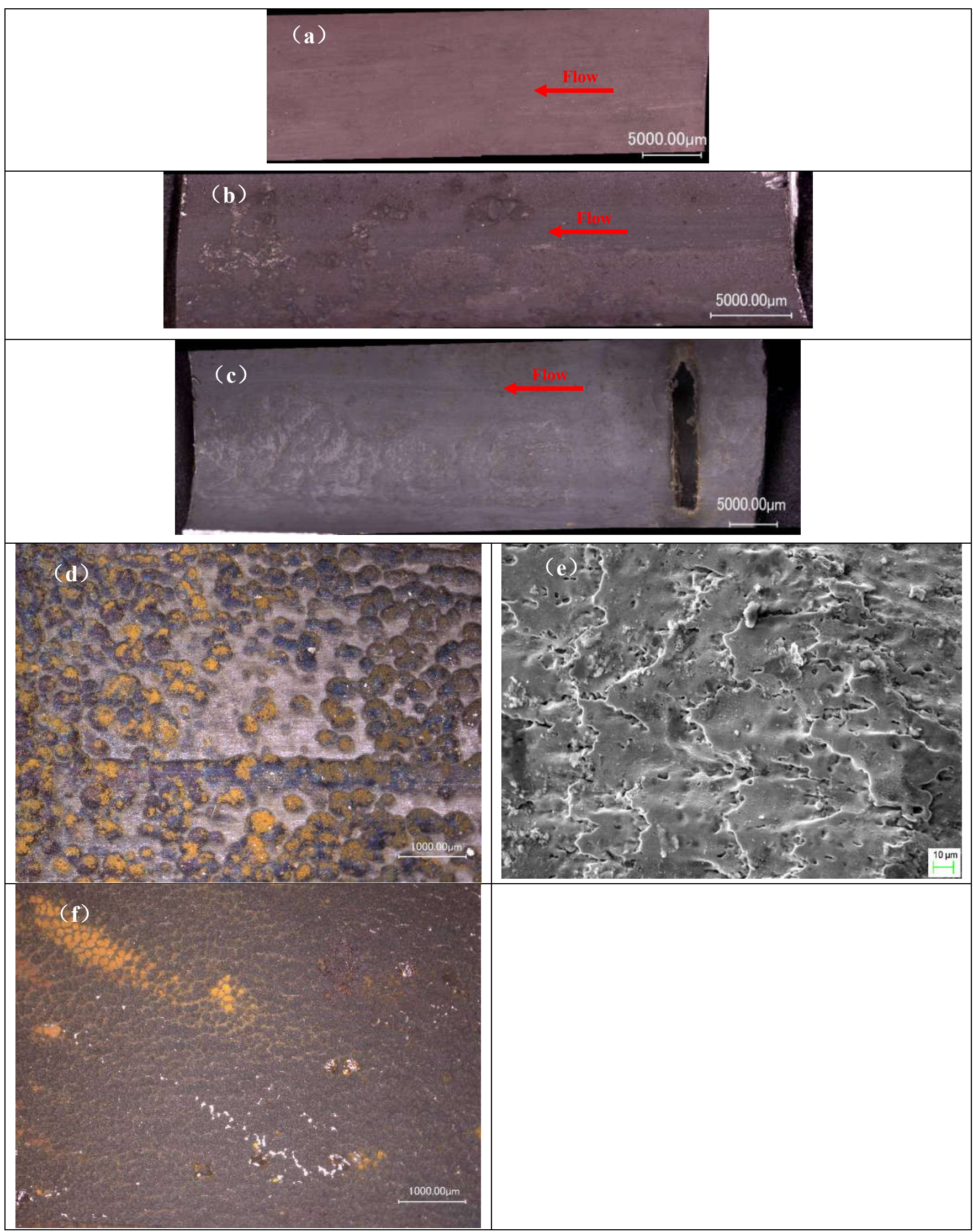




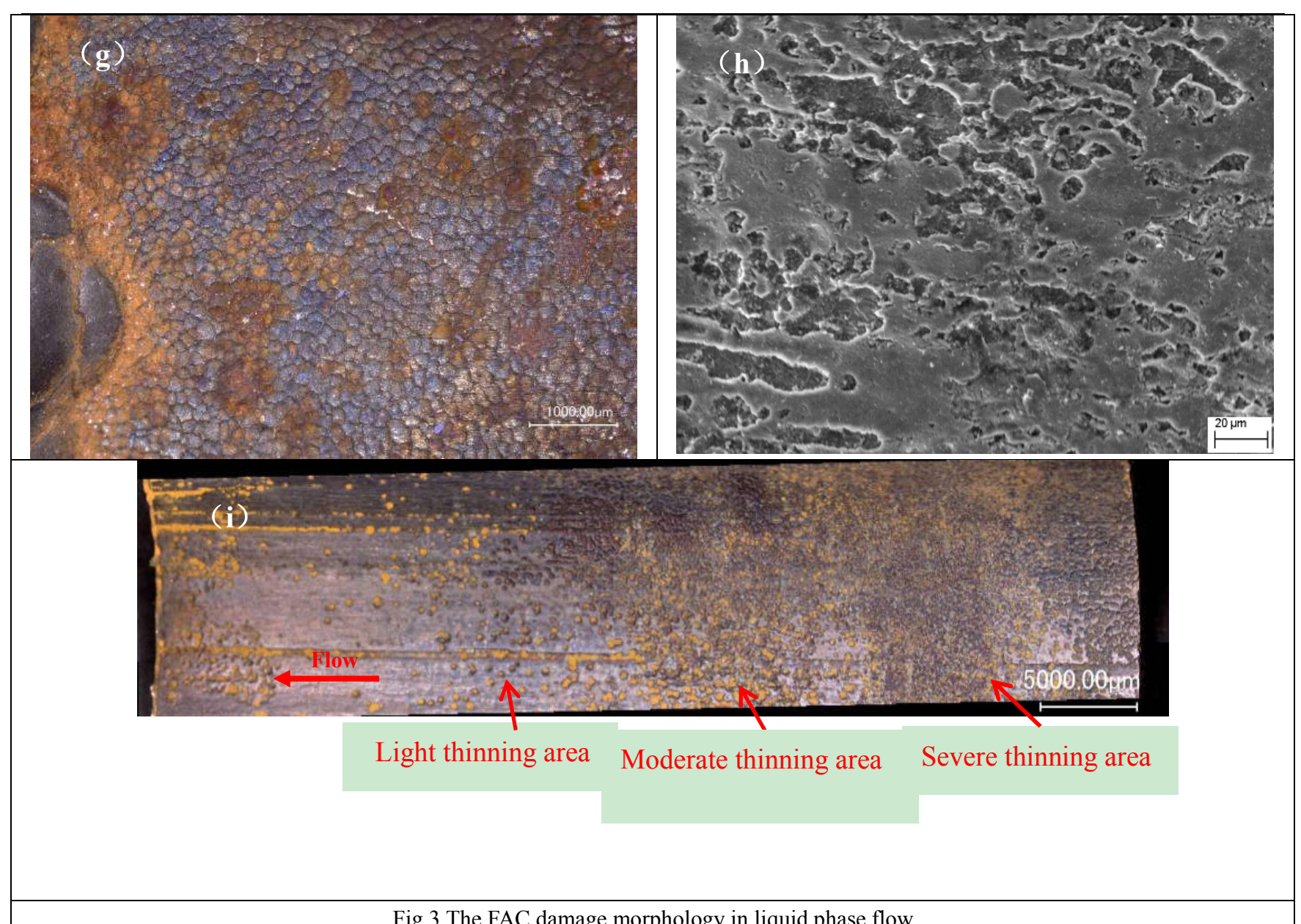

Fig.3 The FAC damage morphology in liquid phase flow

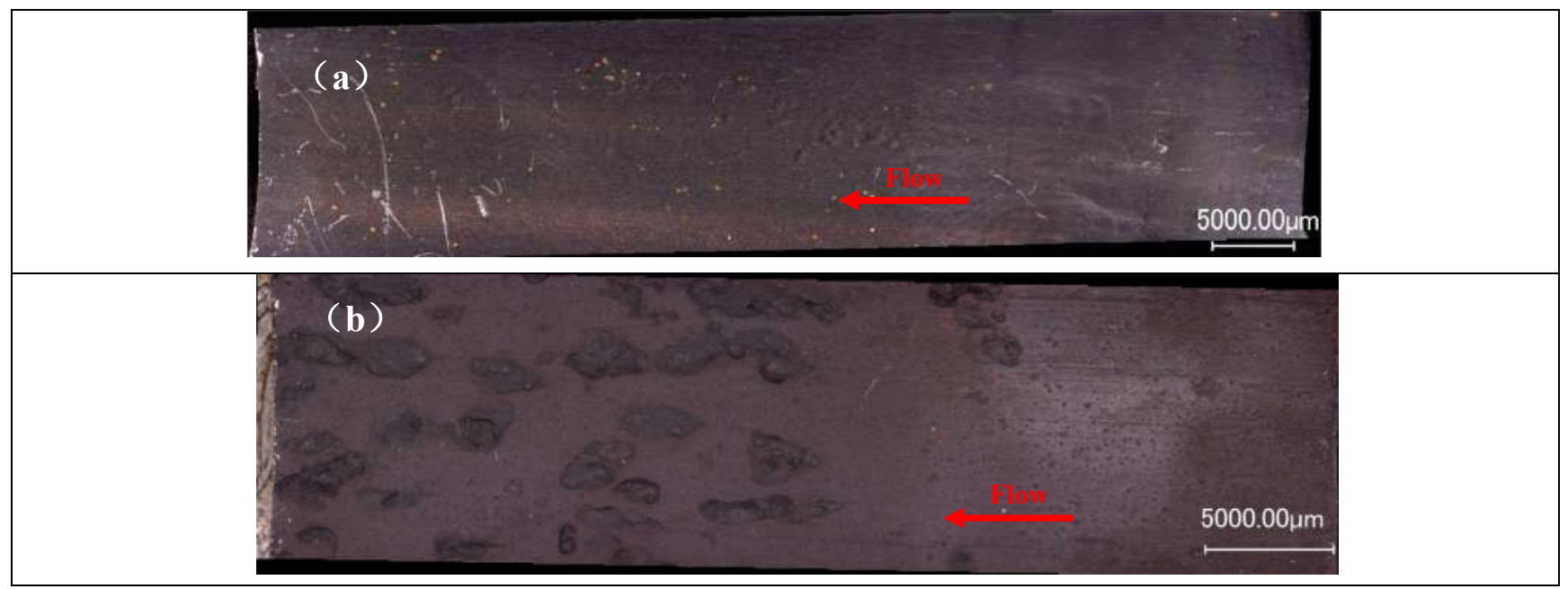




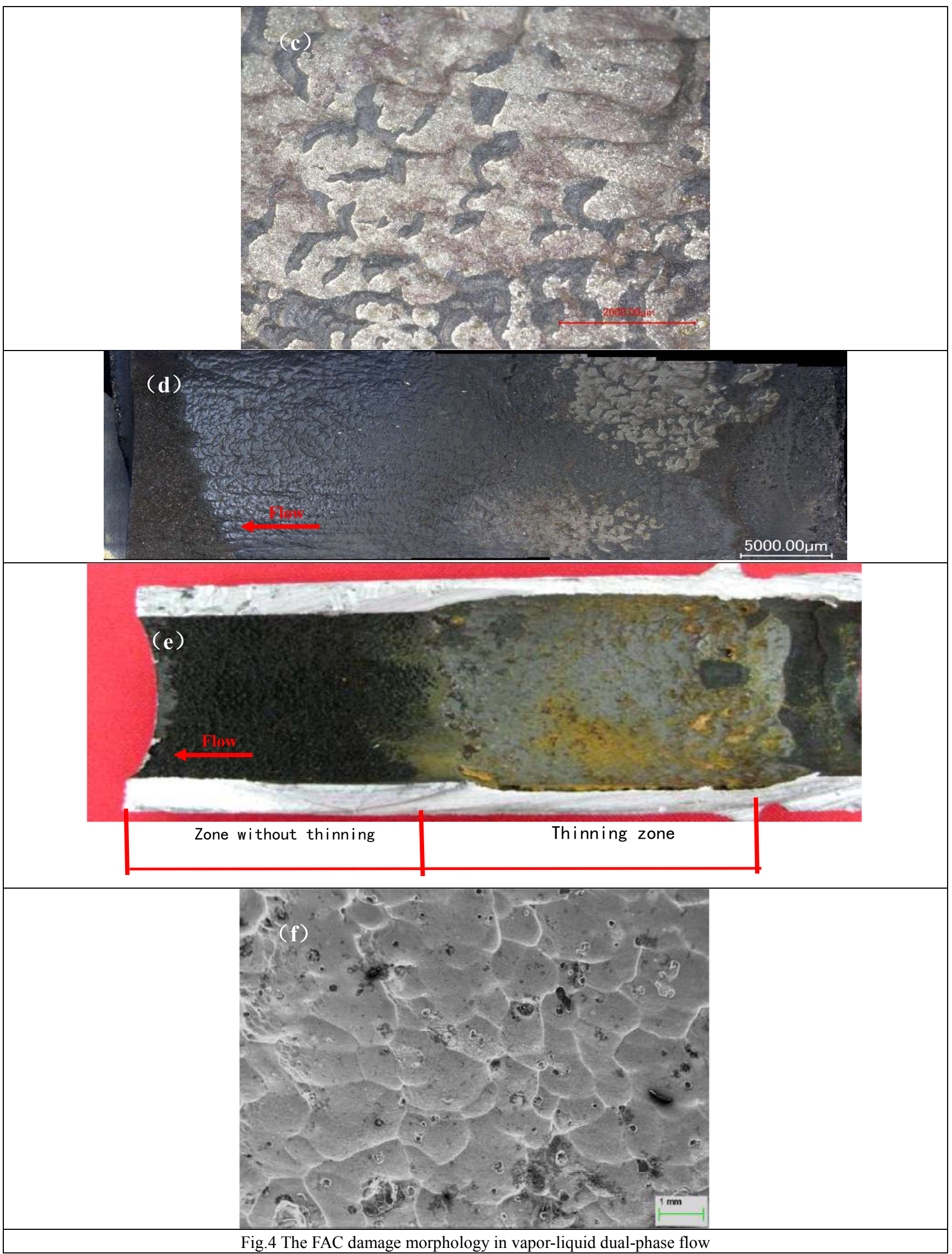




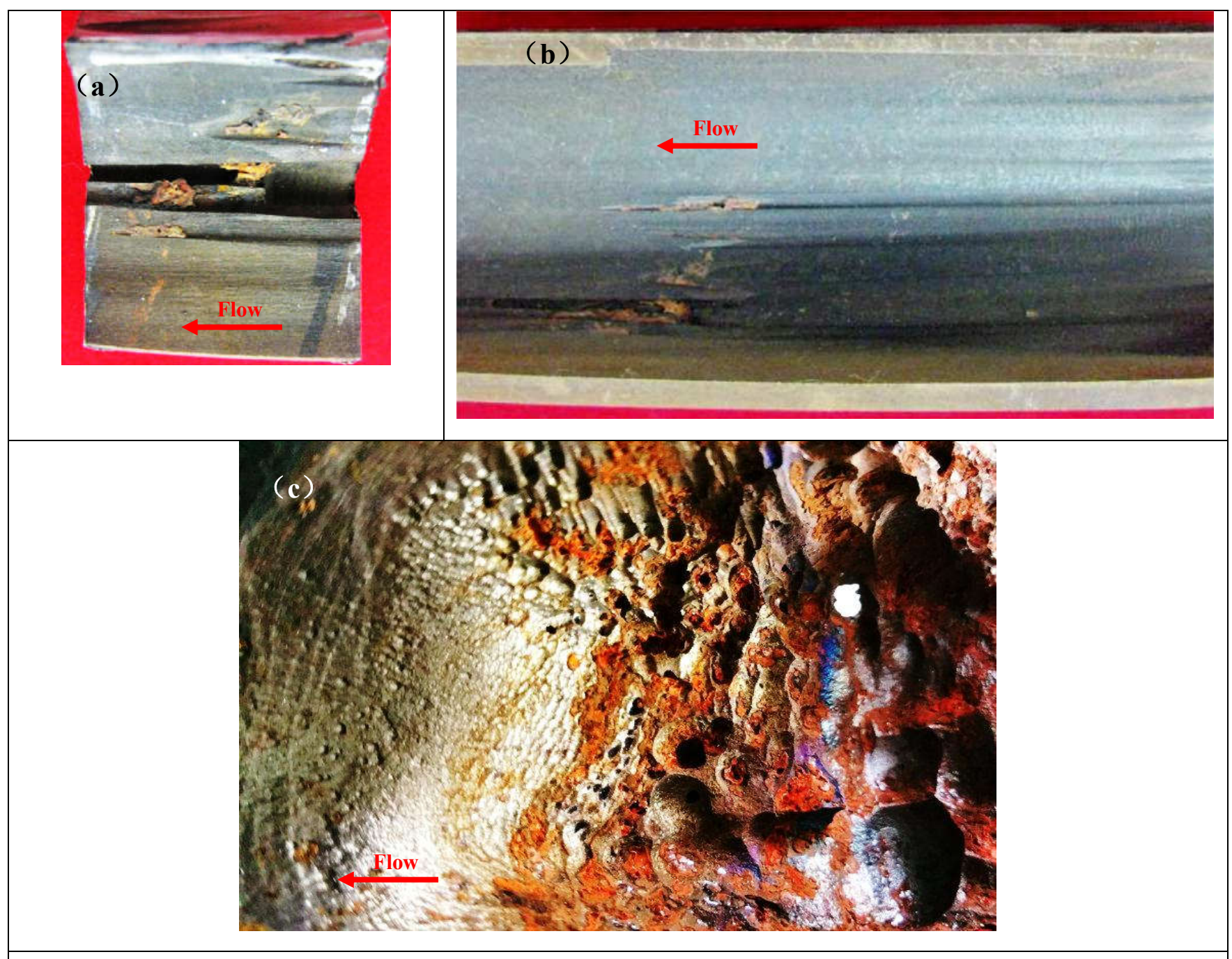

Fig.5 The Flashing, Jet cutting and Cavitation damage morphology
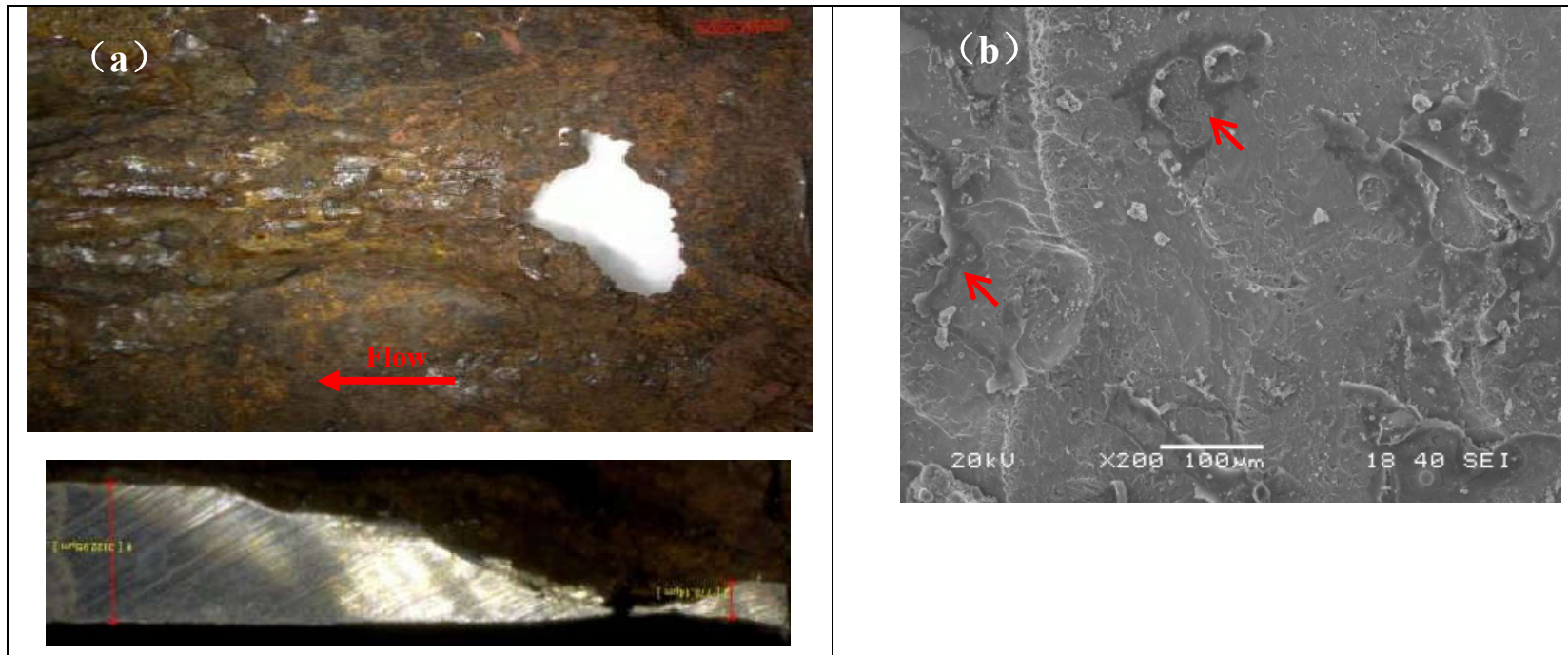

Fig.6 The morphology of HTC and erosion damage 


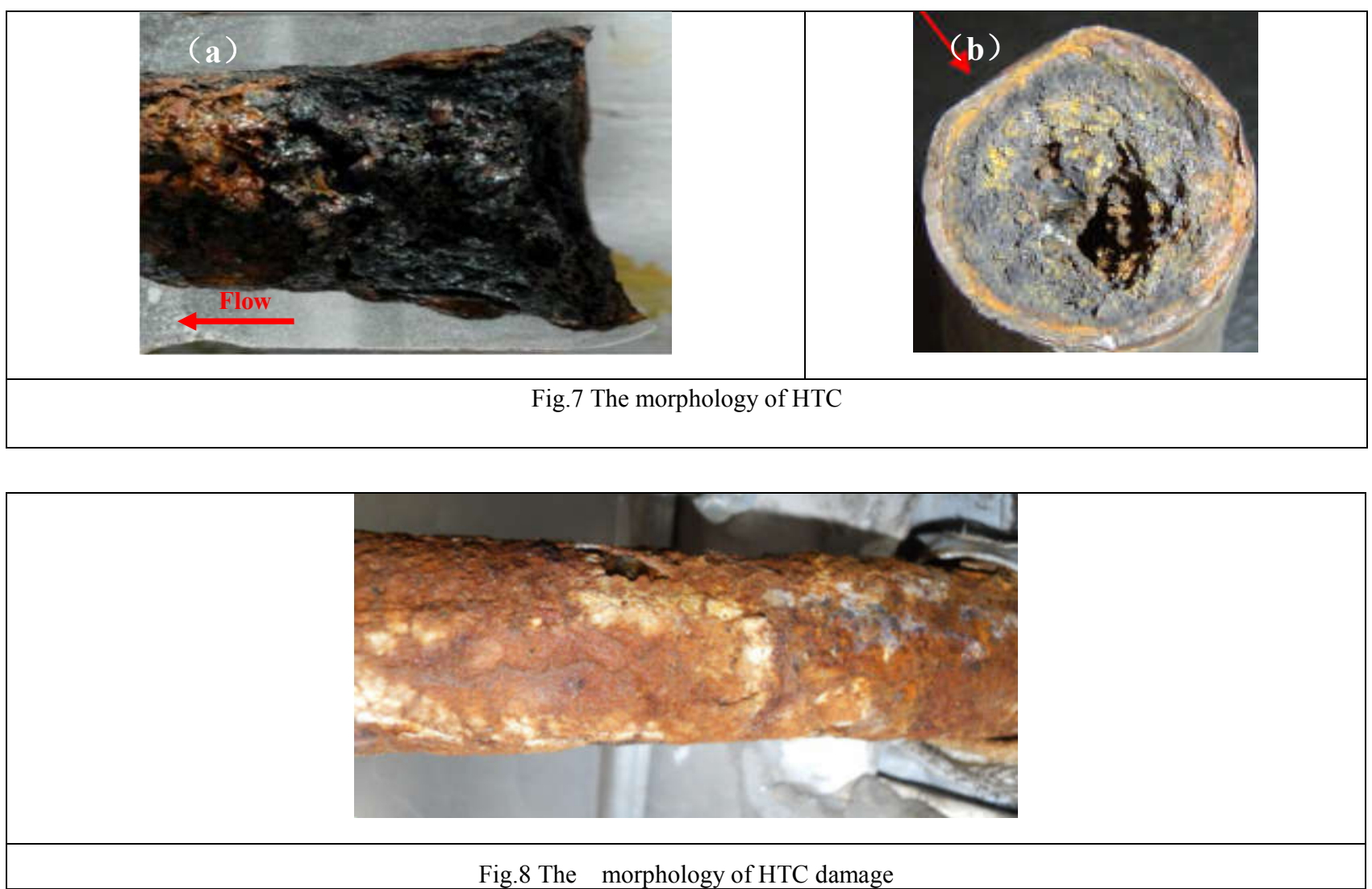

Tab. 1 corrosion damage character of the secondary loop piping in nuclear power plant

\begin{tabular}{|c|c|c|c|c|c|}
\hline Corrosion mode & Flow & Corrosion condition & Morphology & $\begin{array}{c}\text { Thickness } \\
\text { distribution }\end{array}$ & Thinning rate \\
\hline \multirow{2}{*}{ FAC } & $\begin{array}{l}\text { Liquid } \\
\text { phase flow }\end{array}$ & $\begin{array}{c}\mathrm{Cr}<0.3 \% \\
130^{\circ} \mathrm{C}^{\sim} 180^{\circ} \mathrm{C}\end{array}$ & $\begin{array}{l}\text { Orange pee1, more } \\
\text { serious, the pits } \\
\text { more smaller and } \\
\text { closer }\end{array}$ & $\begin{array}{l}\text { Smooth } \\
\text { transition }\end{array}$ & $0.19 \sim 0.3(\mathrm{~mm} / \mathrm{a})$ \\
\hline & Two phase flow & $\begin{array}{c}\mathrm{Cr}<0.3 \% \\
150^{\circ} \mathrm{C}^{\sim} 210^{\circ} \mathrm{C}\end{array}$ & $\begin{array}{l}\text { Tiger stripes, more } \\
\text { serious, the stripes } \\
\text { more bigger and even } \\
\text { get loss }\end{array}$ & $\begin{array}{l}\text { Severe local } \\
\text { thinning }\end{array}$ & $0.2^{\sim} 0.3(\mathrm{~mm} / \mathrm{a})$ \\
\hline \multirow[b]{2}{*}{ Cavitation } & Two phase flow & $\begin{array}{l}\text { The pressure drops } \\
\text { suddenly below the } \\
\text { saturated vapor pressure }\end{array}$ & Flat and smooth & $\begin{array}{l}\text { Smooth } \\
\text { thinning }\end{array}$ & Not measured \\
\hline & $\begin{array}{l}\text { Two phase flow } \\
\text { and liquid } \\
\text { phase flow }\end{array}$ & $\begin{array}{l}\text { The pressure drops } \\
\text { suddenly below the } \\
\text { saturated vapor pressure }\end{array}$ & $\begin{array}{l}\text { Slag blowhole, more } \\
\text { serious, the hole } \\
\text { more bigger and } \\
\text { deeper }\end{array}$ & $\begin{array}{l}\text { Severe local } \\
\text { thinning }\end{array}$ & Rapidly \\
\hline $\begin{array}{l}\text { High temperature } \\
\text { corrosion erosion }\end{array}$ & Two phase flow & $\begin{array}{c}\text { High temperature and high } \\
\text { flow rate }\end{array}$ & river valley & local thinning & $0.5(\mathrm{~mm} / \mathrm{a})$ \\
\hline Liquid drop & Two phase flow & High flow rate & Spot pit & Smooth thinning & Uniform and slow \\
\hline Jet cutting & $\begin{array}{l}\text { Liquid phase } \\
\text { flow }\end{array}$ & High flow rate & $\begin{array}{l}\text { Narrow and deep } \\
\text { groove }\end{array}$ & $\begin{array}{l}\text { Severe local } \\
\text { thinning }\end{array}$ & Rapidly \\
\hline $\begin{array}{l}\text { High temperature } \\
\text { corrosion }\end{array}$ & & $\begin{array}{l}\text { High temperature, } \\
\text { saturated oxygen } \\
\text { and vibration }\end{array}$ & $\begin{array}{l}\text { Large amount } \\
\text { of corrosion } \\
\text { products }\end{array}$ & $\begin{array}{l}\text { Severe local } \\
\text { thinning }\end{array}$ & $0.4(\mathrm{~mm} / \mathrm{a})$ \\
\hline CUI & & $\begin{array}{l}\text { Warm and humid, } \\
\text { saturated oxygen }\end{array}$ & $\begin{array}{c}\text { Loose corrosion } \\
\text { products }\end{array}$ & local thinning & $0.3(\mathrm{~mm} / \mathrm{a})$ \\
\hline
\end{tabular}




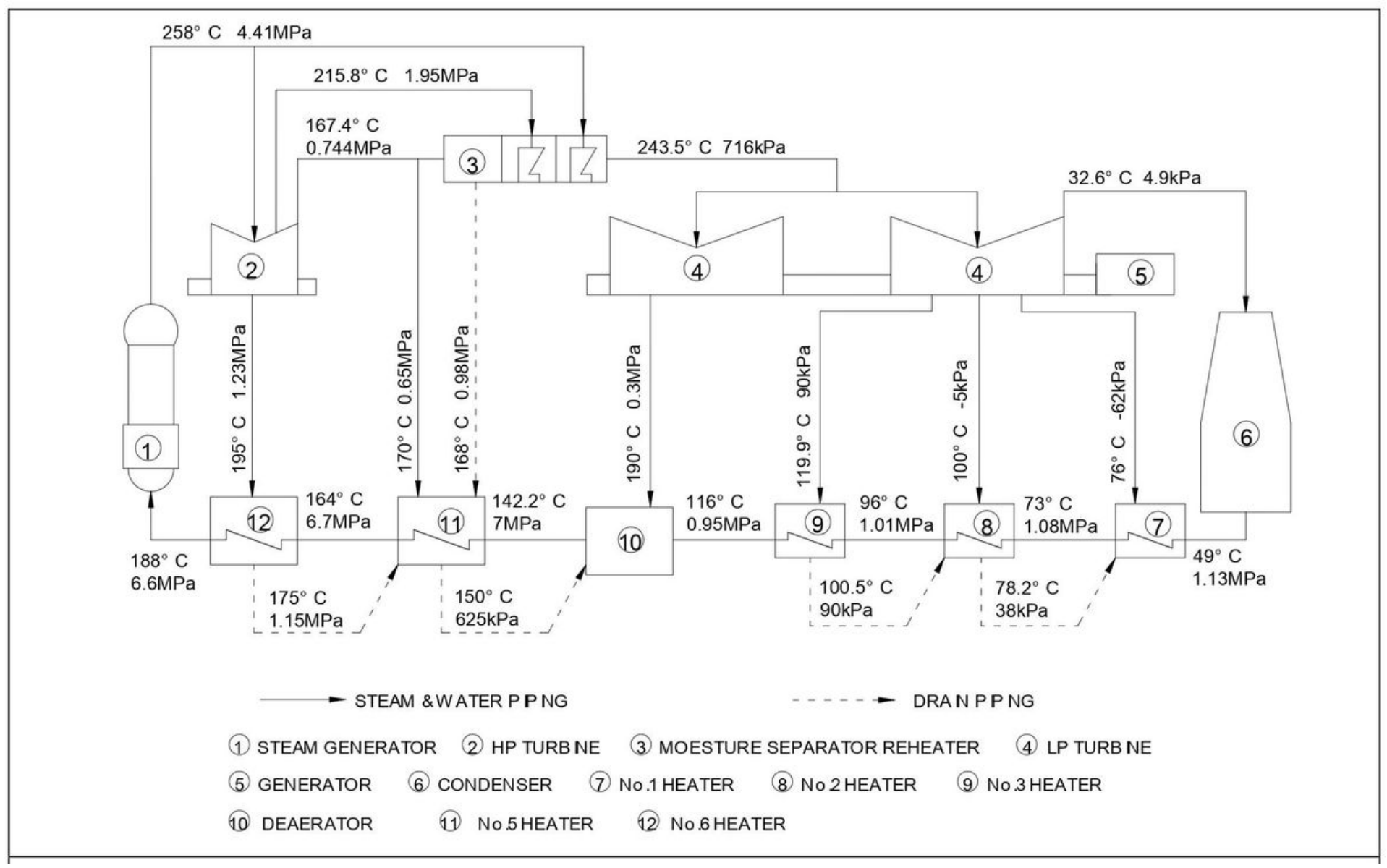

Figure 1

The heat balance diagram of the secondary loop in a nuclear power plant 


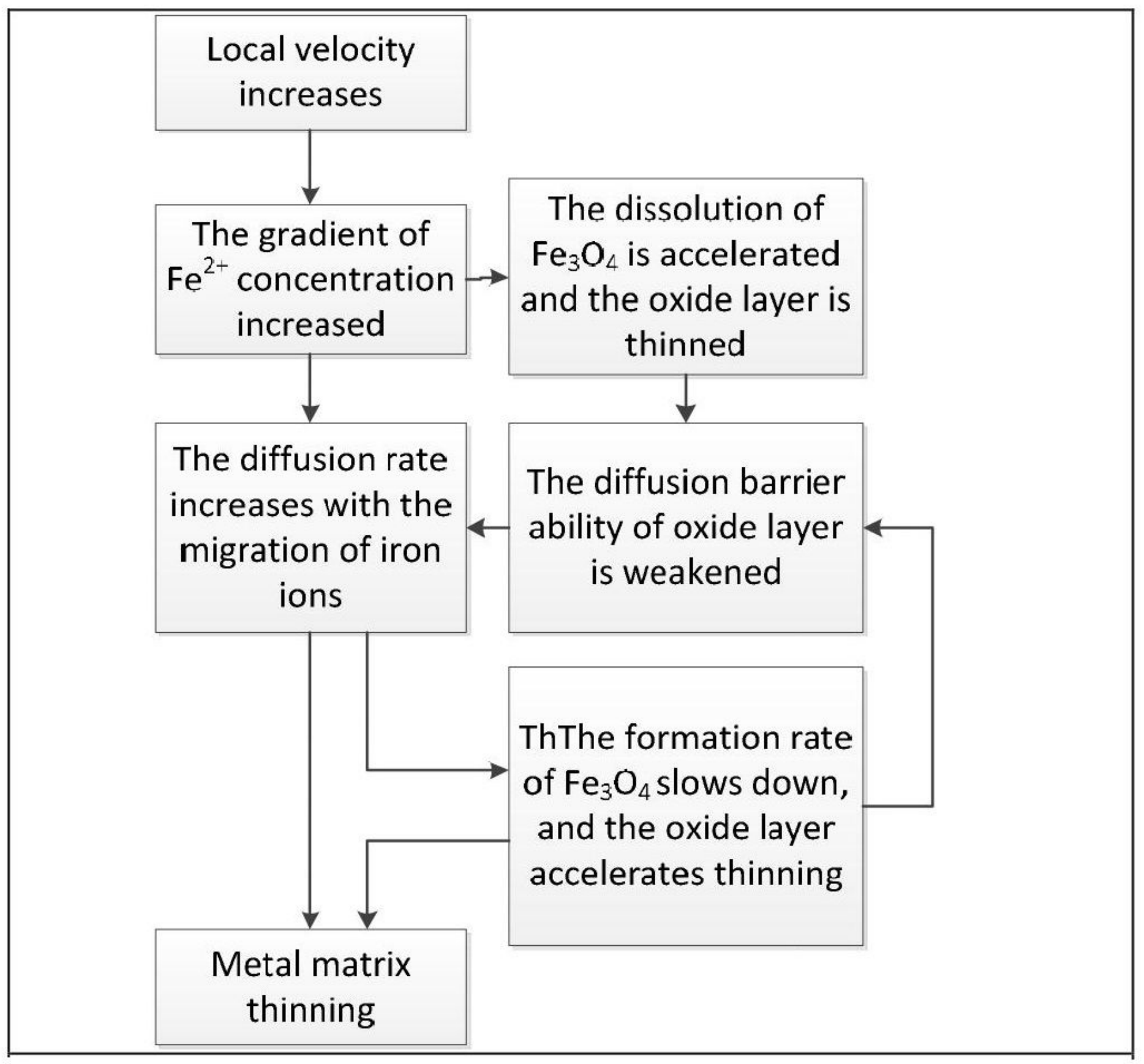

Figure 2

The mechanism of FAC thinning 

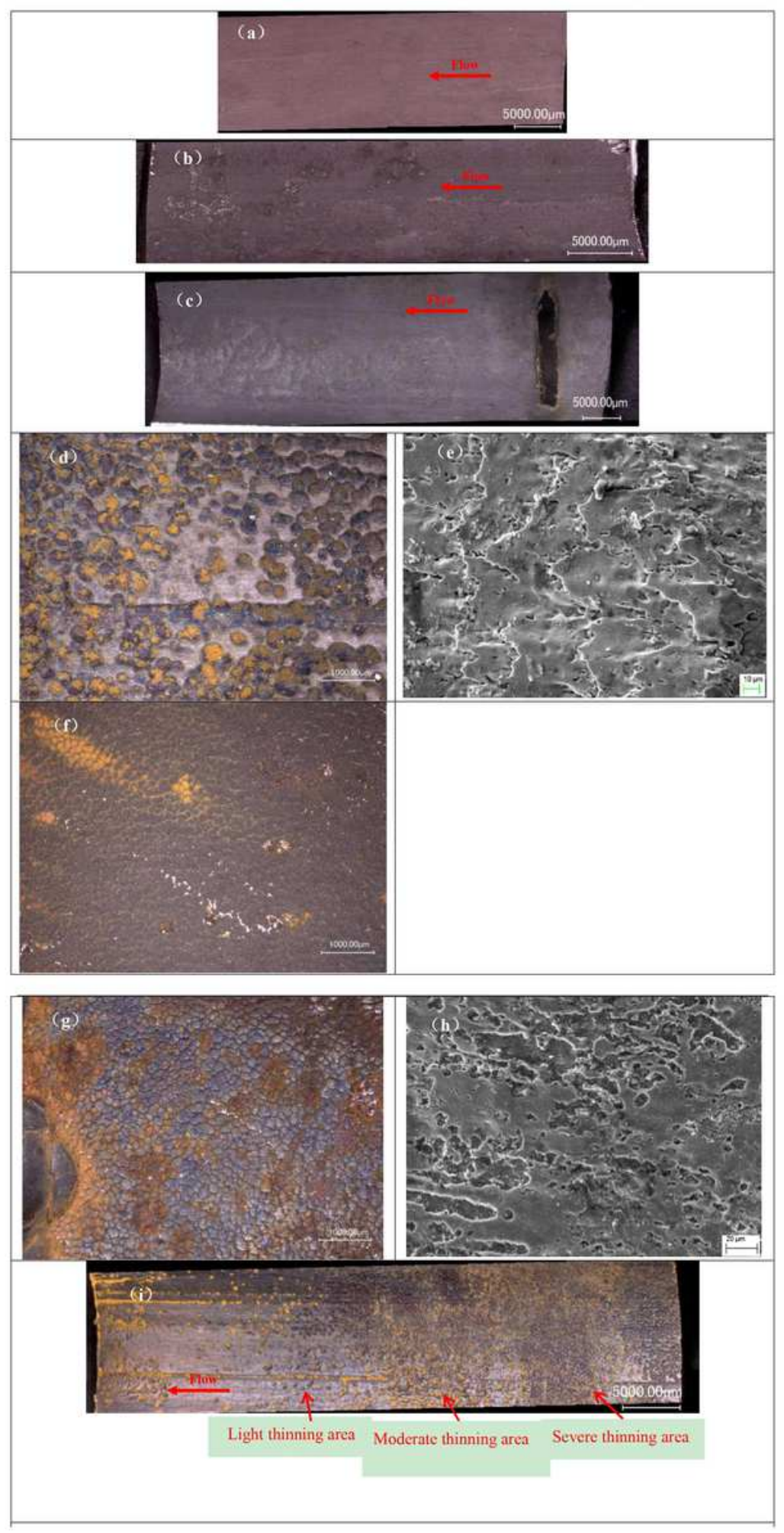

Figure 3

The FAC damage morphology in liquid phase flow 

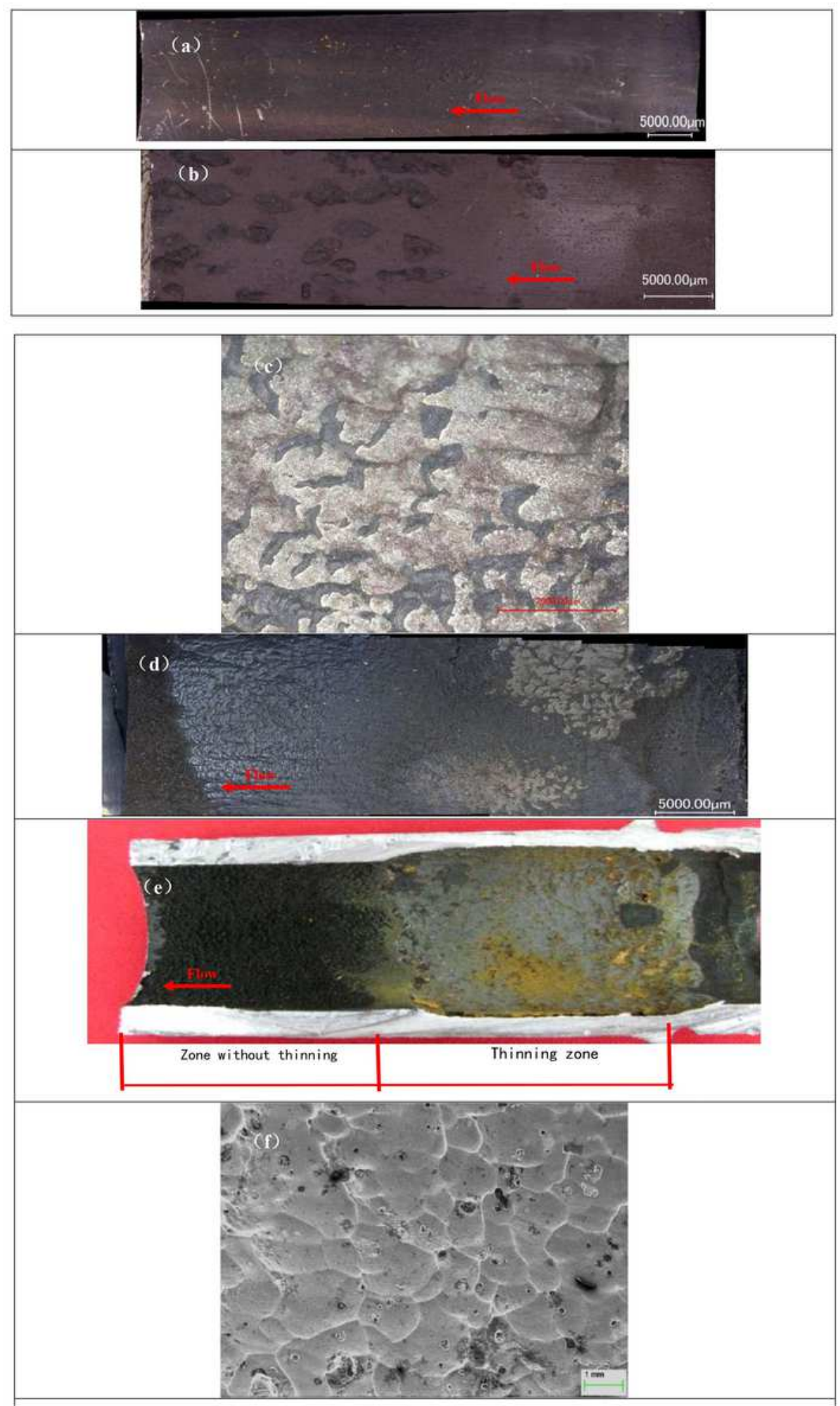

Figure 4

The FAC damage morphology in vapor-liquid dual-phase flow 


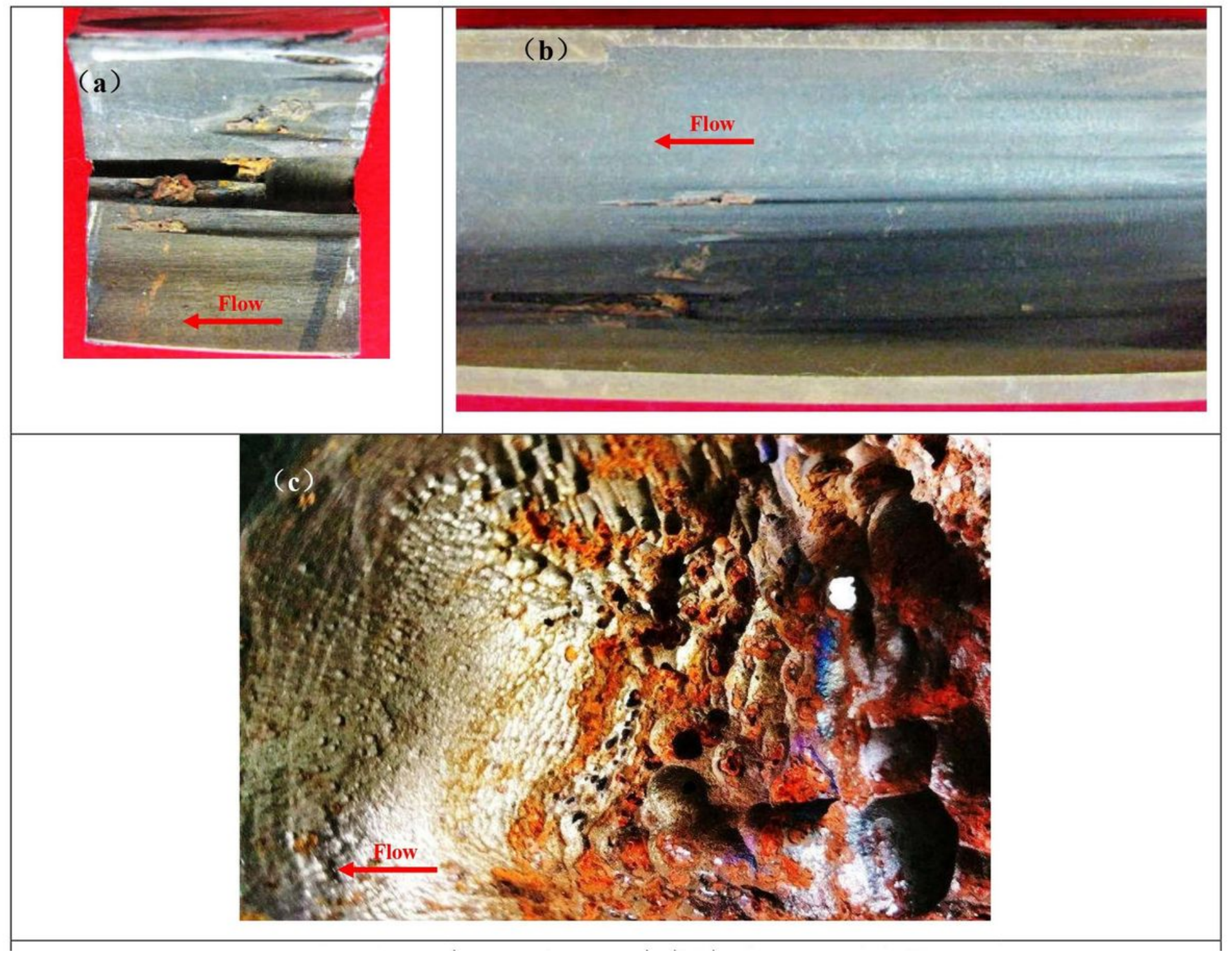

Figure 5

The Flashing,Jet cutting and Cavitation damage morphology 

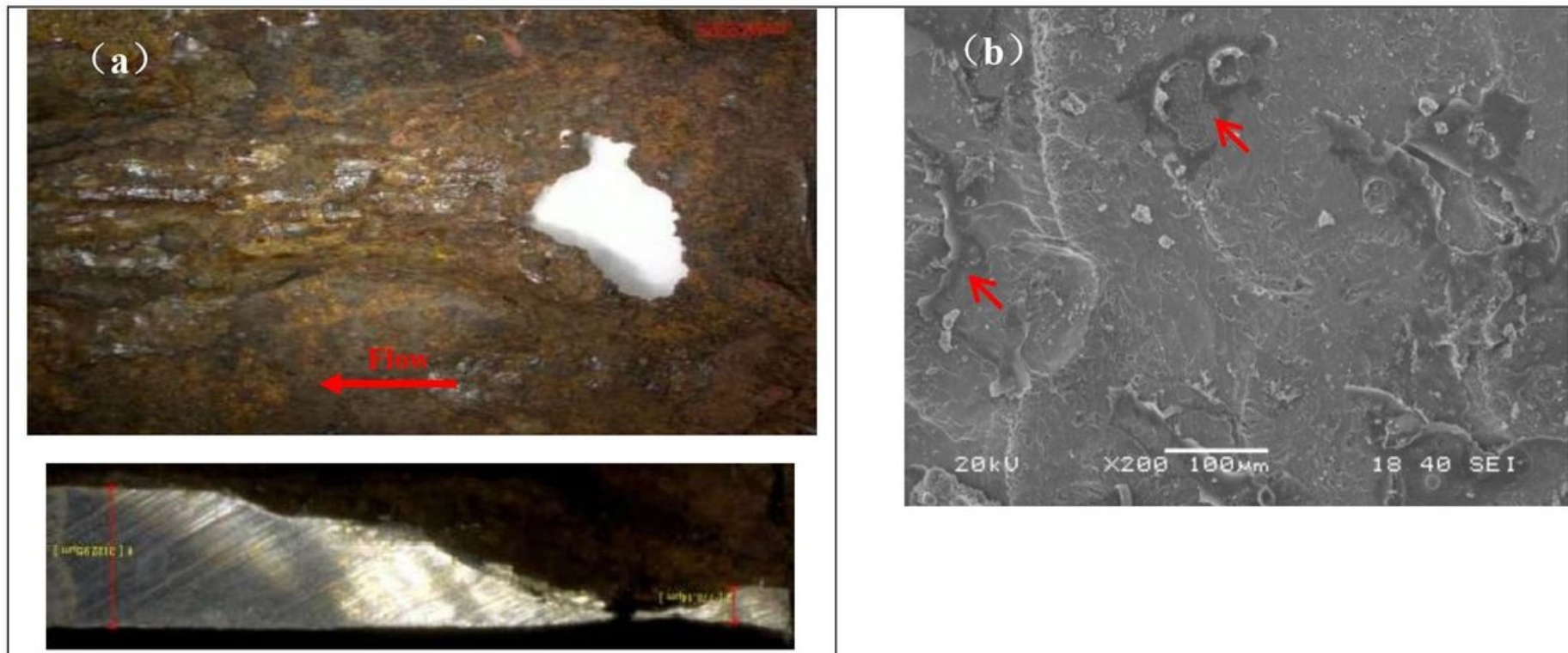

\section{Figure 6}

The morphology of HTC and erosion damage

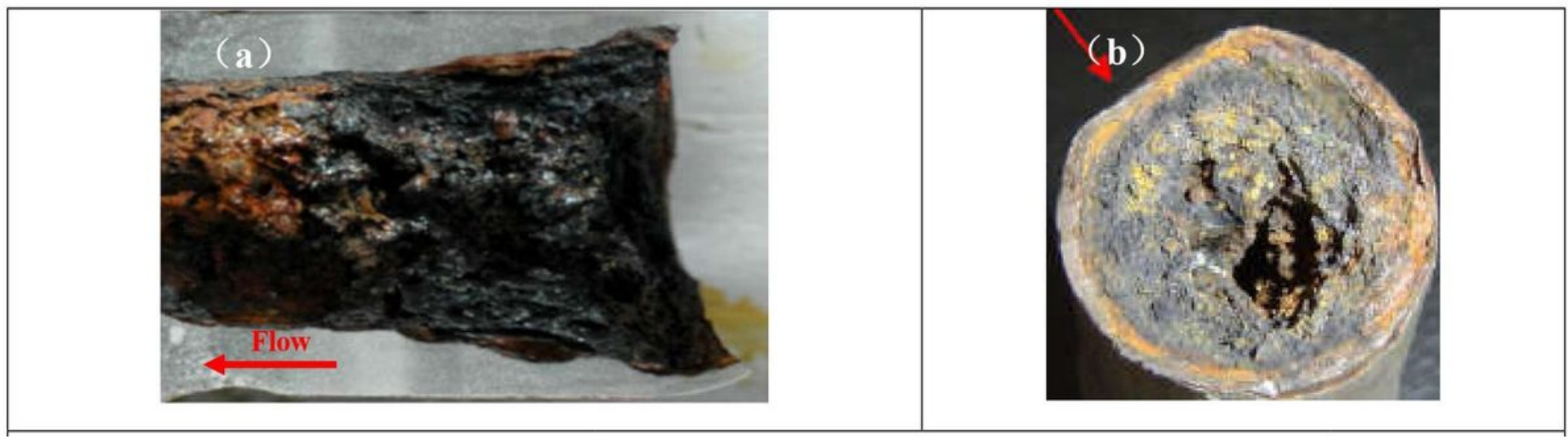

Figure 7

The morphology of HTC

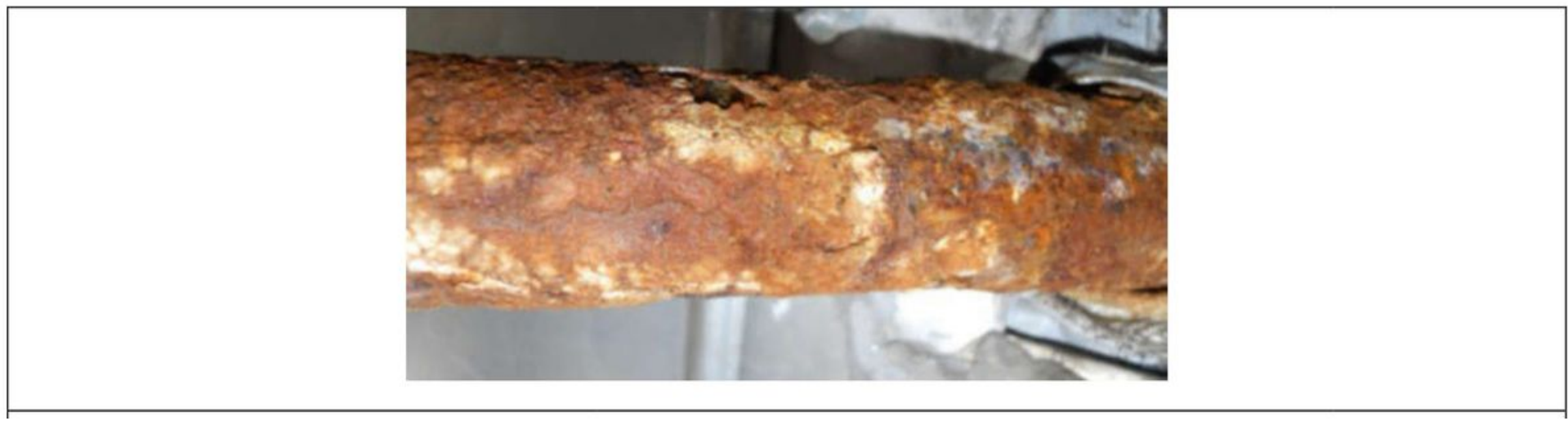

Figure 8 
The morphology of HTC damage 